\title{
The key role of organizational culture in a multi-system view of technology-driven change
}

\author{
Ángel Cabrera ${ }^{\mathrm{a}, *}$, Elizabeth F. Cabrera ${ }^{\mathrm{b}}$, Sebastián Barajas ${ }^{\mathrm{c}}$ \\ ${ }^{a}$ Instituto de Empresa, María de Molina 13, 28006 Madrid, Spain \\ ${ }^{\mathrm{b}}$ Universidad Carlos III de Madrid, Madrid 126, 28903 Getafe, Spain \\ ${ }^{\mathrm{c}}$ Deloitte Consulting, World Trade Center, 08039 Barcelona, Spain
}

\begin{abstract}
Organizations undergoing technology driven change must understand that technology is only one of several inter related components which drive organizational performance. A multi system perspective of organizations highlights the interdependencies between an organization's technology, structure and culture and how these affect organizational processes and behaviors. Successful technological innovations require that either the technology be designed to fit the organization's current structure and culture or that the organizational structure and culture be reshaped to fit the demands of the new technology. Thus, the desired effects of new technology are most often realized in organizations able to implement the additional changes that are required to maintain overall fit. To illustrate these issues, this paper presents a case study based on a technology driven change in a Turkish financial organization. Special attention is given to the role of organizational culture, which is often cited as the most critical factor in successful technology assimilation.
\end{abstract}

Keywords: Organizational culture; Organizational strategy; Technology driven change; Technology assimilation

\section{Introduction}

Anyone who has lived through the implementation of a large scale technological innovation in an organization has run at some point or another into the crude reality of major organizational and human, rather than purely technological problems. Those who have not had the experience firsthand can rely on a 1996 report by the OASIG group that summarizes the experiences of 45

\footnotetext{
*Corresponding author. Fax: +34915610930.

E mail addresses: angel.cabrera@ie.edu (Á. Cabrera), beth@emp.uc3m.es (E.F. Cabrera), sbarajas@dc.com (S. Barajas).
} 
UK leading information technology (IT) researchers and consultants. ${ }^{1}$ According to this report, about $8090 \%$ of IT projects fail to meet their performance goals, and this is in part due to the fact that organizations give inadequate attention to the non-technical, i.e. human and organizational, factors which are critical determinants of the effectiveness of the new systems. IT projects are usually technology-led and address too narrow an agenda, often connected with cost savings. Generally speaking, managers fail to understand the links between technical and organizational issues and between the new technology and the strategic business goals and needs of their organizations.

The same report points out that successful IT implementation requires organizations to adopt an integrated approach to organizational change in which people and technical factors are viewed as inextricably linked and interdependent. In this sense, senior managers must take full responsibility in developing a long-term strategic view of change, and project managers must be given responsibility for managing change, for paying full attention to human and organizational issues, and, more concretely, for actively considering how the new technology may affect the way in which work is organized and jobs are designed.

The purpose of this paper is to present an integrative model to help both administrators and technology designers understand and manage the interconnections between technology and other human and organizational aspects of a business. The ultimate goal is to be able to efficiently manage the changes imposed upon the organization by the introduction of a new technology in such a way as to minimize the human costs of the transition while maximizing the benefits obtained from the technology.

Within this model we will pay special attention to the factors that determine the behavior of the group of people that form a particular organization. By understanding how human behavior is influenced by the particulars of an organization we might be able to clarify the potential impact of introducing a new technology. A useful way of understanding collective determinants of behavior is to appeal to the notion of culture. The first part of the paper is devoted to clarifying this concept, its operationalization, and its relationship with organizational change.

Technology and people, however, are only two of the several subsystems which are at work within the organization and which together define its performance. In order to understand the interconnections between technology and people we need a bigger picture which lays out the relationships between these two and other important subsystems such as organizational structure, business and management processes, and strategy. The second part of this paper presents a general multi-system framework that illustrates the most important dependencies among the major subsystems of the organization.

Finally, for this framework to be of any use, it should be able to help us deal with change. To illustrate how the framework can be used to effectively plan and manage technology-driven change, the last section of the paper describes an experience in which these concepts were applied in the context of a large-scale IT project in a financial institution.

\footnotetext{
${ }^{1}$ OASIG is a Special Interest Group funded by the British Department of Trade and Industry which deals with Organizational Aspects of Information Technology. The referenced 1996 report, entitled "The Performance of Information Technology and the Role of Human and Organizational Factors", can be found at http://www.shef.ac.uk/ $\sim$ iwp/publications/reports/itperf.html.
} 


\section{Culture as a determinant of behavior}

Culture can be broadly understood as "a set of basic tacit assumptions about how the world is and ought to be that a group of people share and that determines their perceptions, thoughts, feelings, and, to some degree, their overt behavior" (Schein, 1996). According to Hofstede (1991) there are three main factors that, at least to some degree, determine the behavior of a person in the workplace: national culture, occupational culture, and organizational culture.

National culture is based primarily on differences in values which are learned in early childhood from the family. These values are strong enduring beliefs which are unlikely to change throughout the person's life. Occupational culture, which is acquired through schooling and professional training between childhood and adulthood, is comprised of both values and shared practices. Shared practices are learned perceptions as to how things should be done in the context of some occupation and are, as such, more malleable than values. Finally, organizational culture is based on differences in norms and shared practices which are learned in the workplace and are considered as valid within the boundaries of a particular organization.

The relative influence that occupational and organizational cultures exert on people's behavior appear to vary significantly across occupations (Mintzberg, 1978; Schein, 1996; Trice \& Beyer, 1993). Some professional groups (such as physicians) have acquired exclusive rights to perform certain kinds of work, to control the training requirements for performing that work, and to regulate how the work is performed and evaluated. Because the work of these professionals is so severely constrained by these rights, the occupational cultures associated with them are quite immune to administrative practice. The behavior of these professionals is more strongly determined by their occupational culture than by the culture of the organizations in which they practice. On the contrary, the behavior of other less regulated professionals (e.g. the administrative staff of a hospital) will be more prone to influences from the culture of the organization.

From the point of view of technology design and implementation, national culture can be an important issue in transferring technology across nations, designing systems with culturally diverse teams or deploying systems for users from different cultural environments. In terms of occupational culture, some researchers have found that dysfunctional interactions among the different professional groups involved in IT projects are often the cause of deficient implementation. Schein, for example, has observed some strong differences in basic assumptions held by engineers, operators and top executives. Whereas engineers saw networking technology as an opportunity to eliminate cumbersome hierarchy, executives saw hierarchy as a necessary mechanism for control and coordination. Whereas engineers saw expert systems and MIS (management information systems) as excellent tools to improve management decision making, executives felt unnecessarily constrained by them. Being aware of existing occupational differences can help us manage implementation more effectively. As Schein has argued, "organizations will not learn effectively until they recognize and confront the implications of [their different] occupational cultures" (Schein, 1996).

\subsection{Organizational culture}

Organizational culture, which will be the focus of this paper, can be thought of as a pattern of basic assumptions and beliefs, developed by a given social group throughout its history of internal 
integration and external adaptation, that has worked reasonably well in the past to be considered by the group as valid and important enough to be passed on to new members as the "correct" way of interpreting the organization's reality (Schein, 1990).

Organizational culture comprises a set of social norms that implicitly define what are appropriate or inappropriate behaviors within the boundaries of the organization. Organizational culture is not necessarily homogeneous across all areas of the organization. While some of the norms will permeate the entire organization, different groups within the organization might develop their own sub-cultures.

Assessing an organization's culture is not an easy enterprise, due in part to the fact that the actual underlying values and norms do not necessarily correspond with the officially espoused ones, not even those espoused by the top executives (Argyris \& Schön, 1978). Several methods have been devised to conceptualize and assess organizational culture. Here we will concentrate on the framework proposed by Hofstede. We justify this choice because (a) this framework is relatively easy to map onto organizational issues and is therefore useful for effectively managing change, and (b) because there are commercially available tools that allow practicing managers to apply this framework at a relatively low cost in real settings.

In one of their studies, Hofstede, Neuijen, Ohayv, and Sanders (1990) assessed the values and perceptions of daily practices of employees from 10 different organizations, five in Denmark and five in the Netherlands. A major finding of this research showed that, independently of observed national culture differences (which corroborated the results of an earlier study by Hofstede (1980)), organizations varied in the way their practices were perceived by their respective members. In-depth statistical analyses revealed six main dimensions of cross-organizational variability: (1) process vs. results-orientation, (2) employee vs. job orientation, (3) parochial vs. professional identity, (4) open vs. closed communication system, (5) loose vs. tight control, and (6) normative vs. pragmatic mentality.

Process vs. results orientation refers to whether an organization is more concerned with the means and procedures that must be followed to carry out the work or with the goals that are pursued with that work. Process orientation is typical of mechanistic or bureaucratic organizations rich in rules and procedures, whereas results orientation is typical of organic, risk-taking organizations, in which mistakes are well tolerated and innovation is valued.

The employee vs. job orientation reflects whether the organization is more concerned with the well-being of the person or with getting the job done. Groups or committees often make the important decisions in employee-oriented cultures, and an effort is made to help new members adjust. On the contrary, job-oriented cultures tend to rely on individual, top-down decision making.

The parochial vs. professional dimension reflects the weight that is given to the occupational cultures of the members of the organization. In parochial organizations, employees identify strongly with their organization, whereas in professional cultures employee identify more with their profession. In hiring new employees, parochial organizations rely on social and family background information, whereas professional cultures hire on the basis of job competence alone.

An open or closed system refers to the communication climate within the organization. In an open system culture information flows easily through the organization, whereas closed cultures are more secretive. Interestingly, Hofstede et al. (1991) found that organizations with more women at the top management were more likely to have an open culture. 
Organizations also vary in the amount of control they exert over individuals. Tightly controlled cultures, for example, may observe strict meeting times and show a strong cost-saving consciousness. Loose control organizations are more permissive about individual's preferences (e.g. public jokes about the company are accepted).

Finally, organizations vary in their degree of conformity to institutional pressures. Pragmatic cultures are more market driven and are open to ad hoc solutions, while normative cultures are more concerned with following institutional rules. Meeting customer needs is a major objective in pragmatic cultures while normative cultures are more interested in adhering to the "correct" procedures as a way of obtaining legitimacy (Hofstede, 1980).

The culture of an organization is initially connected to the values of its founders, as well as the socioeconomic, regulatory and institutional environment of the organization. Culture is maintained and transmitted through stories, rituals, symbols and practices. One of the key determinants of organizational culture is the way in which the organization manages its employees, or, in other words, the organization's human resource (HR) management practices (Cabrera \& Bonache, 1998). The HR policies (staffing, training, compensation, performance appraisals, career management, recruiting, etc.) send messages to the employees as to what behaviors are considered desirable and, hence, they determine the shared practices which define, according to Hofstede, the organization's culture.

Unlike national and occupational cultures, organizational culture can be, at least to some extent, modified. By the time a person enters the organization, their national and professional cultures are already in place. Being aware of them can be helpful to better manage technological innovations, but there is nothing that we can do to change them. On the contrary, there are several levers that, given the need, the time and the resources, management can attempt to move in order to influence and shape the organization's culture (Miles \& Snow, 1978). This potential manageability of organizational culture makes it particularly interesting from the point of view of implementing technology-driven change.

\section{A multilevel view of organizational performance and change}

Why is organizational culture so important from the point of view of implementing technological innovations? As we will see, a new technology can impact the very nature of the work being carried out to the point of imposing new requirements in the behaviors that are expected from users. Whether or not a technological innovation ends up yielding the intended results will in part depend on whether the behavioral requirements it imposes are compatible with the current culture or whether the current culture can be altered so as to become compatible with those requirements.

Aligning technology and culture is not an easy task, among other reasons because they both interact with other key organizational subsystems: the organization's formal structure and procedures, its processes and its strategic intent (i.e. the objectives it ultimately attempts to accomplish). The model in Fig. 1 will help us to clarify these complex interconnections (Ruddle \& Feeny, 1997). This model is a manifestation of the so-called sociotechnical systems perspective (Pasmore, 1988), an approach to organizational design according to which every organization consists of two complex and inter-coupled systems: the technical and the social system. Organizational effectiveness is considered to be a function of how well the social and technical 


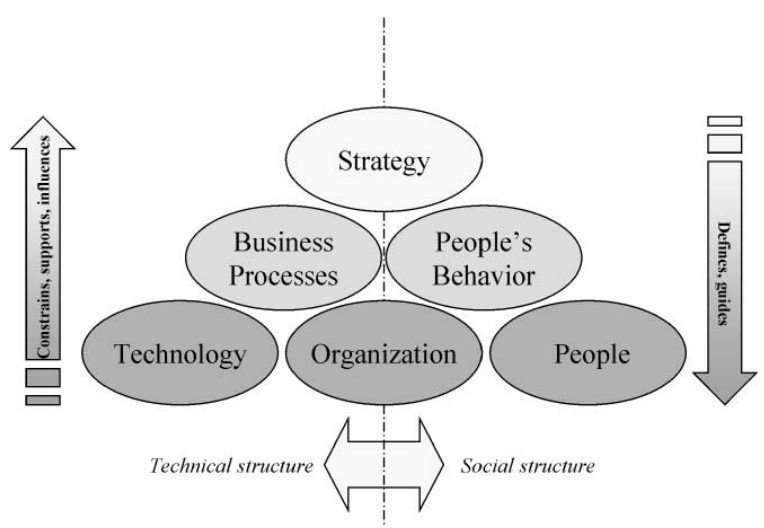

Fig. 1. A multi system framework of organizational performance.

systems are designed with respect to one another and with respect to the demands of the outside market. Our model, however, expands on this distinction by establishing three different levels of analysis of organizational performance: the strategic level, the capability level and the infrastructure (or architecture) level.

The bottom level, which we will refer to as the infrastructure or architecture level contains the long lasting pieces of the organization: the organization's technology, its structure and its people (including the set of managerial practices that regulate the relationship between the organization and its members). This infrastructure supports the system of complex activities carried out by the organization and which include business processes and behaviors. The organization's processes and behaviors form the capabilities of the organization.

Finally, if we step back and take a more holistic view of the activity of the organization, we find the organization's strategy. Strategy refers to the way in which the organization sees itself in relation to its stakeholders (customers, providers, shareholders, employees, government) and to the ways in which the organization chooses to employ its resources in order to satisfy the needs of its stakeholders. The strategic level of analysis deals with questions such as what types of clients the organization tries to serve, what objectives of quality and/or cost the organization seeks to accomplish, what kind of value the owners of the organization expect to obtain, and what kind of work environment the organization is trying to provide for its employees (Porter, 1996).

In a sense, we can think of the organization as a real life theater play. The architecture level includes all the necessary components without which the play could not take place: the stage, the costumes, the script, the actors, the technicians and the director. When the curtain is raised and the actors and technicians engage in action, operating the different devices and prompts and interacting with one another as prescribed by the script, a flow of dramatic action emerges. These are the "processes and behaviors" of the play. Finally, one can step back and reflect on what the play is actually about. We can ask, for example, about the expected emotional response in the audience, about the level of technical and artistic mastery achieved by actors and technicians, and about ticket box outcomes. This level of discourse would correspond to what we have called the strategic level of analysis of organizational performance. 
Whether or not the organization is able to achieve its strategic objectives will depend on whether it can deploy the right kinds of processes and behaviors, which are in turn determined by the organization's architecture. So, lower levels determine what can and cannot happen at upper levels. For example, a hospital group lacking digital communications infrastructure will hardly be able to develop the capability to carry out certain distance diagnoses. This limitation will in turn restrict the kinds of services that this group can offer patients attending its satellite units (strategy). If for some reason we introduce a change in one of the infrastructure subsystems (a change in technology, in organizational structure or in how the human resources are managed), we will impact the capabilities of the organization and, hence, the chances of the organization achieving its objectives. For this reason, changes at lower levels should always be informed and guided by an analysis of implications at upper levels and should be ultimately linked to the organization's strategy.

This does not imply that change initiatives must necessarily come from the organization's top management. New technological developments known to the technical staff can open up strategic opportunities that may have never been considered by the management alone (Kirn, 1997). What the model implies is that, even when the changes are initiated by a technological innovation, their successful implementation requires an analysis of the effects the changes may have on the capabilities and strategic intent of the organization.

In summary, the model underlines the importance of aligning the different subsystems of the organization along two complementary dimensions. On the one hand, there needs to be a coherent connection among strategy, capabilities and infrastructure. This is what we will call vertical fit. But at the same time, following the indications of the sociotechnical systems perspective (Pasmore, 1988), the model emphasizes the importance of aligning the social and technical components of the organization. This is what we call horizontal fit. At the capability level, horizontal fit implies integration between business processes and people's individual and social behavior. At the infrastructure level, horizontal integration implies integration among technology, organizational structure and people. For example, a new information system that automates administrative procedures and integrates client information could eliminate the need for back office administrative work while increasing the functions of current customer service jobs. In order to adapt to the new situation, current back office personnel could be transferred to customer service departments (an organizational re-arrangement). This, however, might create a conflict between the subculture of the former administrative people (not used to dealing with the end customer) and the service orientation that is required by the new jobs. In order to deal with this misalignment we might need to create specific training programs or redefine performance appraisal procedures (HR interventions).

\section{The framework in action: managing change}

Before engaging in any major change process, it is important to have a clear and integrated picture of (a) where the organization stands now, and (b) where we want the organization to be (Fig. 2). We will call the current state of affairs the "as-is" organization, and the desired state of affairs the "to-be" organization. The definition of the "to-be" is fundamental in order to establish a clear direction for all changes. The analysis of the "as-is" is necessary for understanding the 


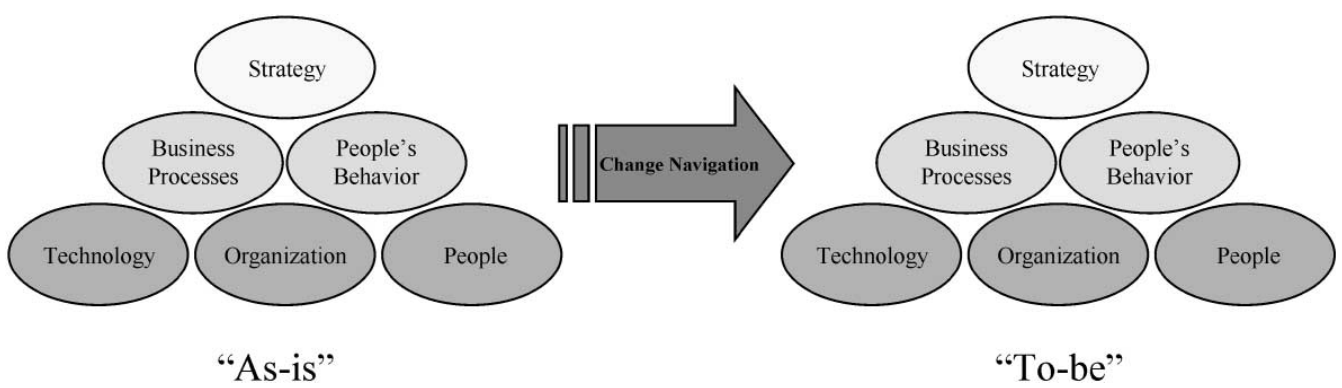

Fig. 2. Change management diagram.

feasibility of the proposed changes and the most likely barriers. The comparison between the "tobe" and the "as-is" will help us identify and prioritize the interventions that will be necessary to make the transition: they will help us navigate through the transition. To illustrate how this framework can help manage change we will describe our experiences in a large-scale technologyled change at a financial institution in Turkey.

\subsection{The context of the change}

The organization that we will be referring to is one of Turkey's top five commercial banks in terms of number of branches, number of employees and net profit. As of 1995 this bank employed over 7000 persons divided between its head office departments (around 2000 employees) and a network of about 400 offices distributed throughout the entire country. In the 1970s and 1980s the banking sector in Turkey had been highly profitable due in part to protectionist regulations that limited competition. These regulations started being eased in the early 1980s under the influence of renovated European standards. This deregulation helped foreign banks to enter the market, which contributed to the creation of a more competitive environment and thus jeopardized historic profit margins. As a consequence of these changes, most Turkish banks were convinced of the need to streamline their processes so as to become more cost efficient and to reorganize in such a way as to improve their capacity to continuously adapt to future market evolutions.

Within this context, our Bank decided to put together a large, international team with the objective of designing and implementing whatever organizational and technological changes were necessary for the Bank to maintain and even improve its competitive position in the Turkish market. There was a shared understanding that these changes would most likely include a heavy IT component. In fact, the largest portion of the project budget was dedicated to upgrading the bank's information systems infrastructure from its current old-fashioned main-frame based systems to a state-of-the-art integrated client server architecture.

However, given the magnitude of the changes that were expected, significant resources (about $20 \%$ of the total budget) were dedicated to anticipating and managing organizational and human issues. The fact that an expert in change management was appointed as leader of the entire project is a good indicator of the importance that was attributed to human issues. This leader emphasized that, independent of the magnitude of the resources dedicated to developing the IT, the project 
was about changing the organization to be more successful, and not about upgrading the technology for its own sake.

The project team was made up of an average of 120 people, including analysts from the Bank and outside consultants. The team was structured around three main groups: a group dedicated to redesigning the IT platform (the Technology group), a group dedicated to the reengineering of business processes and the functional design of the information systems (the Process group) and a group dedicated to organizational and human issues (the Change Management group). Whenever necessary, multidisciplinary teams were set up including also line employees to carry out specific tasks.

\section{Strategy: setting up the master plan}

Starting from the top of the model, we need to understand the main variables governing the strategic positioning of the organization in its market (Porter, 1980). Here are some questions that we might find useful to ask in order to reach a sufficient understanding of these issues.

- Positioning. What distinctive value is the organization trying to offer to its customers and how is it going to manage to survive to do so? Does the organization primarily focus on maintaining low costs, on providing a differentiated service, or on excelling in a particular niche? Knowing the general positioning of the organization can inform us about the organization's priorities, about what it expects from investments in technology and, hence, about how success will be measured.

- Perspective on innovation. Organizations vary in the way they face innovation (Miles \& Snow, 1978). Defenders are organizations that focus primarily on improving the efficiency of their operations without actively searching for new market opportunities. They compete by maintaining lower costs than their competitors. On the contrary, prospectors are organizations which are constantly innovating, experimenting, and trying out new products and services that give them a "first-to-market" advantage privileges associated with offering unique products and services. Finally, analyzers are organizations that maintain a stable position in their core business while keeping an eye on competitors and trying to rapidly adopt those innovations that appear to have the greatest potential. Knowing where the organization stands with respect to innovation can also reveal important information about what the organization may expect from its investments in technology.

- Current corporate plans. Are there any ongoing or upcoming corporate plans to expand or reduce services or client base? Corporate plans which may appear to be unrelated to our projects might actually have a great impact on our chances of success. An upcoming merger with another organization might cause prior systems integration efforts to become useless or even counterproductive. Geographic expansions may have implications for networking and communication requirements. Outsourcing plans might limit the interest in investing in certain types of systems. Because an organization's capacity to assimilate change is not unlimited, we need to make sure that the changes imposed by our new technology are not too overwhelming.

Unfortunately, finding satisfactory answers to these questions is not straightforward. Strategy is often only tacitly embedded in the actions of the organization and official documents and plans 
rarely capture the reality of what the organization is actually trying to accomplish (Mintzberg, 1978). So, in order to get a more realistic picture of the organization's strategic intent one has to dig a little deeper. From a methodological point of view, a possible action plan would include a few early strategy clarification sessions with top-managers and decision makers from each of the affected areas of the organization. Several group techniques have proved useful in guiding such sessions (see Higgins, 1996 for a review).

In the case of our Bank, several strategy clarification meetings were set up in which top executives discussed, with the assistance of an external facilitator, what they perceived to be the main threats and opportunities faced by the bank in the current market and in the immediate future. These discussions were guided by quantitative and qualitative data showing the Bank's performance in different areas as compared to that of key competitors. Members of each of the project's three groups also attended these meetings. These meetings helped clarify the bank's objectives. For instance, it seemed that the Bank was particularly interested in specific market segments and wanted to tailor their products and services to the needs of those segments. Also, they saw themselves as a quick and efficient bank (in terms of internal costs and customer convenience) and wanted to emphasize those strengths. Finally, they wanted to reinforce the consistency of their bank-wide services.

In addition to clarifying these goals, the meetings served to:

- Send a message to all project managers about the business objectives of the Bank for which the technical and organizational efforts would be instrumental.

- Reach a consensus among the Bank's management as to the Bank's priorities and expectations from the project.

- Document the Bank's vision for the immediate future in a way that could serve as a reference point for all the persons involved in the project (during the meetings the term "McBank" was coined to reflect the desired bank-wide service consistency and this term transmitted a very clear message to all team members about this particular expectation of the Bank's top management).

- Increase the level of commitment of the Bank's top management to the objectives of the project. This commitment was later key in obtaining their involvement and sponsorship for the implementation of the different interventions in their respective business areas.

\section{Capabilities: laying out the play}

\subsection{Processes}

The strategic expectations of the organization need to be translated into business process and behavior specifications. Bringing strategic intent down to processes specifications can be done according to widespread business process reengineering (BPR) techniques (Hammer, 1996; Hammer \& Champy, 1993). Based on a specific strategic intent and knowledge of the opportunities offered by the new technology, BPR yields (a) a redefinition of key processes, (b) a set of functional requirements for the design or adaptation of the new technology, (c) a set of task descriptions that serve as input for the redesign of the organization's structure, (d) a set of 
measures of performance for evaluating the new processes, and (e) specific recommendations as to the kinds of behavioral patterns and attitudes required to carry out the new processes.

Knowing the strategic perspective of the organization with respect to innovation can be useful to determine which processes should receive more attention. "Defender" organizations will most likely be concerned with gradually decreasing costs and increasing efficiency of current processes, often through mechanization of practices (Miles \& Snow, 1978). "Prospector" organizations, on the contrary, will be more interested in processes needed for the creation of new products and services and will probably be willing to trade process efficiency and routinization for flexibility. Finally, "analyzers" will be more concerned with processes underlying the efficient adoption, implementation and marketing of innovations that have proven valuable elsewhere.

In the case of our Bank, we were dealing with an analyzer profile. Market studies showed that clients saw the Bank as modern and innovative, but the top management thought of the bank more as a well oiled machine. The Bank was good at adopting new products and services, but it was best at efficient distribution. Given the strategic emphasis on efficiency, the process reengineering tasks focused on improving major commercial processes connected with customer service (automating administrative tasks, integrating operations and centralizing data), but some effort was also spent on improving product development processes.

\subsection{Behavior}

When we try to define optimal behavioral patterns based on strategic considerations the notion of organizational culture becomes most relevant. Initial accounts of organizational culture in the 1980s (Ouchi, 1981; Peters \& Waterman, 1982) considered that there were particular cultural configurations which led to organizational success. For instance, it was believed that culture "strength" the degree of consensus and identification of organizational members with the dominant norms could lead to organizational success. These prescriptive views of culture have lost momentum over time, in part due to difficulties in explaining some renowned organizational failures. For example, IBM, a role model to early authors in terms of cultural strength and organizational "excellence", ended up experiencing great difficulties adapting to the dramatic changes in the computer industry in the late 1980s in part due, ironically, to the strength of its culture.

More recently, researchers have moved towards a contingent approach according to which a culture (weak or strong) will be an asset for achieving organizational success so long as it encourages the kinds of behaviors that are critical for the organization to successfully compete in its environment (Miller, 1993, 1994). So, whereas a process-oriented culture might be prescriptive for an organization following a defender strategic profile, that same orientation could be fatal for a prospector organization. The key is to find a cultural configuration that guarantees both horizontal and vertical fit.

Although there is still not a "behavior reengineering" methodology as well structured and tested as BPR, there are several things that we can do to try to identify the cultural profile that could meet the requirements of the "to-be" organization. ${ }^{2}$ In our case, we expanded our

\footnotetext{
${ }^{2}$ The term "human reengineering" has appeared in the management literature (Cooper \& Markus, 1995), however not with the meaning that is implied here, but rather as a reference to methods to overcome employee's resistance to change.
} 
strategy clarification meetings with a series of sessions in which (a) we explored the concepts of culture and organizational culture, (b) we analyzed the connection between strategy and culture, (c) several subgroups were identified within the organization as potentially requiring distinctive profiles, and (c) a consensus was reached as to what general cultural and subcultural profiles were most adequate in order to achieve the strategic objectives previously identified, given the user requirements that would presumably be imposed by the upcoming technology.

In particular, a distinction was made between central service departments in the head quarters and the activity of the branches. For example, head quarter departments were thought to require process orientation as a means to guarantee process efficiency and reliability, whereas the branches were seen as ideally risk-taking and commercially proactive, thus more in line with a results-orientation.

What is important at this point is not just to draw a picture of the ideal cultural profile of the organization but to draw this picture in reference to the current situation. In our case, we did this by applying Hofstede's model of organizational culture. The Bank was divided into 10 target groups that were considered a priori to be likely to show differences. The divisions were both hierarchical and functional. A random sample from each target group was tested with Hofstede's tools, yielding measures along each dimension. In addition to the current culture, respondents were also asked to assess their "desired" culture, i.e. what the culture of their ideal workplace would be.

This assessment of organizational culture was important for several reasons. First, it allowed us to detect possible misalignments between the current culture and the requirements of the to-be organization. For instance, the assessment revealed that administrative employees who had held back office jobs in the past had developed a strong means-oriented subculture. If these people were to be assigned to commercial positions requiring a results (rather than a means) orientation, some actions would have to be carried out to facilitate the transition.

Second, the culture assessment can help detect organizational strengths on which to rely during the change process. In our case, one such strength was detected along Hofstede's parochial vs. professional dimension. Following a tradition of strong investments in training and development, the Bank had achieved an overall positive attitude towards learning. In fact, working for the Bank was perceived among business school undergraduates as an excellent career opportunity. A positive attitude towards learning is usually associated with a professional (rather than parochial) culture, and our assessment confirmed this prediction. This information led us to believe that certain change management interventions would be more successful if framed in terms of professional development.

Finally, a culture assessment can help detect (and therefore prepare for) potential resistance to change. Alignment between the culture employees wished they had (the "desired" culture) and the culture the top management wished they had (the "optimal" culture) could reflect a predisposition by the people to change in the prescriptive direction. In other words, this situation would signal that employees agree with management about the changes that are to be undertaken and will therefore be open to any initiative that would make the change possible. On the contrary, if the "desired" and "optimal" cultures differ with one another, resistance can be expected. 


\section{Infrastructure: setting up the play}

\subsection{Technology: designing the stage}

If one follows the steps that we have described, by the time one reaches this point, there are clear references as to what role the technology is expected to be playing in the to-be organization. Furthermore, one hopefully has a clear idea that technology alone may not suffice to enable the expected changes.

In terms of technology design, we must have collected several pieces of information that can be of great relevance. First, the new definitions of the work processes yield clear requirements for the design, in terms of the functionality that needs to be satisfied and in terms of how that functionality must be coordinated with existing processes and technologies. Second, our ideas about the strategic characteristics of the organization can give us clues as to what sorts of technologies might be better received. For instance, organizations with a defender profile those seeking to provide services more efficiently will tend to favor the development of a single, integrated core technology (Miles \& Snow, 1978). Prospectors, on the other hand, will tend to avoid long-term commitments to a single technology because doing so could hinder their capacity to innovate. Prospectors will feel comfortable investing in prototypes of new technologies and maintaining a high mix of different technologies. Finally, analyzers will maintain a dual scenario with a core, integrated technology that guarantees process efficiency and a moderate amount of other, innovative technologies that can become integrated in the long run.

In the case of our Bank, the departing point was a high mix of technologies, which had resulted not from aggressive innovation, but from unfavorable historical evolution of computer technology. The proposed technological change included the integration of systems and data into a unified and efficient core information system built over a client server architecture that would facilitate the adoption of future developments.

\subsection{Organization: writing the script}

The process modifications introduced by the new technology can have significant consequences for the nature of the tasks that need to be carried out and the distribution of responsibilities and definitions of jobs. So, we need to ask: Which old tasks have been automatized and are therefore no longer necessary? Which new tasks appear with the new processes? Which tasks will be qualitatively or quantitatively modified?

Tasks are the building blocks of job definitions. Any change in the nature of tasks requires a reevaluation of current job definitions. Organizational design requires the clustering of new tasks into jobs and the redefinition of report lines, especially if the new processes impact the distribution of decision making responsibilities. More often than not, organizational design results in a number of old jobs becoming obsolete, some new jobs being created and some others being significantly redefined. If these changes are significant, a transition plan should be devised. Based on the competence and cultural profiles of the old and the new jobs, the transition plan specifies what persons will be assigned to what jobs and what training actions must be carried out to facilitate the change. 
In our case, the most important change in the structure of the organization was the fact that most administrative positions in the bank's branches were no longer necessary. In the "to-be" organization, the branches were considered as distribution channels with purely commercial responsibilities. So, consequently, most administrative tasks were either automated by the new systems or centralized at the headquarters. While the headquarters would be able to absorb some of the administrative personnel no longer needed in the offices, most of them had to be recycled to meet the needs of commercial positions.

A transition plan was elaborated in which the persons best prepared to change jobs were identified and the necessary training programs were developed. In addition, the definition of the new jobs and the demographics of the persons who were going to be holding those jobs suggested some additional design specifications for the information systems under way, especially in the areas of user interface design and on-line support. Notice that it is not until we have a clear idea of the nature of the new jobs and future job holders that we can actually complete the design of the user-oriented parts of the information systems. This further emphasizes the importance of the notion of horizontal fit discussed earlier.

\subsection{People: casting the actors and rehearsing the play}

Finally, we arrive at the most delicate and complex of the subsystems: the human resource architecture that sustains the people needed by the organization. Organizations try to deliberately influence their people in order to generate needed patterns of behavior. They do so by deciding how to recruit and select their employees, how to train and develop them, how to evaluate their performance, how to compensate them for their work, how to communicate with them, and how to manage them during their work hours.

For instance, a company that wants to emphasize efficiency and cost savings will tend to organize its staffing through internal recruitment, will help its employees gradually build their skills through extensive training programs and will base performance evaluations on efficiency measures (Miles \& Snow, 1978). On the contrary, a company that lives off innovation will tend to use external recruitment of specialists, will spend time and resources identifying and recruiting people with the needed skills and will tend to rely on results-based evaluations of performance.

From the point of view of managing change, it is important to determine (a) which people in the organization will be most impacted by the upcoming changes, (b) how these people are currently being managed, and (c) which discrepancies might exist between the current state of affairs and the behaviors required by the to-be organization.

In our case, the evaluation of the people affected by the changes and the way they were currently being managed included, in addition to the aforementioned culture assessment:

- A demographic study by target group (back-office personnel, tellers, client-service representatives and marketing people) which included, among other data, age, sex, education level, time in the organization and in-company training. The importance of gathering this kind of information cannot be overemphasized. Without knowing what the target population is like it is impossible to know what we can reasonably expect from them. In our case, this study helped us elaborate an organizational transition plan that took into consideration the peculiarities of each target group. 
- A study of the Bank's current communication architecture which assessed how much and how well information flowed through the different areas and levels of the organization. The assessment focused on employee satisfaction with the amount of information received, the perceived trustworthiness of information sources and the effectiveness of available channels (including anything from periodic meetings to e-mail). The survey prompted respondents to consider situations of prior technical or organizational change. Managing change is to a great extent about sending the right message to the right people at the right time. With an assessment like this we were able to identify not only what the most efficient communication channels were, but also who was the most trustworthy spokesperson for each group. This information helped us elaborate a detailed communication plan aimed at paving the way for the upcoming changes.

- An assessment of dominant leadership styles. Studies of organizational change reveal that some leadership characteristics, such as degree of involvement of subordinates in decision making, have a positive effect on the acceptance of change. Failure to solicit subordinates input in the planning of the changes and not informing them appropriately are common sources of resistance toward change (Reichers, Wanous, \& Austin, 1997). In our case, a survey was administered to test how employees in different units and at different levels perceived the effectiveness of the leadership style of their direct supervisors. Contrary to what the top management had anticipated, lower level employees saw their leaders as mostly autocratic and not very inclined to soliciting (not to mention accepting) subordinate input in major decisions.

- An assessment of current human resource practices. In order to figure out how to induce the necessary changes in behaviors, it is important to analyze what current practices might be influencing the behaviors and attitudes that need to be changed. If we want to increase the use of a certain technology, we need to determine which HR practices might be contributing to the currently low levels of utilization. Perhaps the technology is aimed at increasing customer service quality while current HR practices are rewarding workers for quantity and speed of services. Perhaps the HR practices are such that employees have nothing to win or loose by using the technology. It is very important to understand the main HR practices in place and how they relate to the behaviors we are trying to change. Finally, we need to have an idea of how easy or difficult it might be to alter these practices: very often we will find strong institutional pressures which will constrain our possible interventions (pressures from labor unions, general work regulations, government by-laws, etc.).

Changing the collective behavior of large groups is not an easy task. Few HR interventions take effect immediately. Behavioral changes rely on individual learning processes that take time. The bigger the change, the longer it takes. On occasion, the change would require so much time and effort that it might be easier to adapt other aspects of the organization to the current culture than the other way around.

If we decide that the current culture might be hindering the future of the organization and we are convinced of the need to adapt it, then it is important that we carefully plan a sequence of intermediate objectives and actions, as well as methods to evaluate our progress. That is, in addition to determining what river the organization needs to cross, we need to identify what stepping stones can help the organization cross it. Information gathered about the organization's current strengths and weaknesses can help us to identify how large a step the organization can take at one time, and this can help us toset up a realistic agenda of objectives and timing. 


\section{Conclusions}

Organizational culture is a key construct in understanding and managing the behavior of people within the boundaries of an organization and in implementing organizational change. But organizations are complex systems that include several other interlocked subsystems. At first glance we can distinguish between a technical and a social subsystem. Then, at varying levels of abstraction we can look at the organization's infrastructure, its capabilities and its strategy. This paper has tried to provide a general view of the main interconnections between these subsystems and has tried to illustrate how this view can help an organization to more effectively manage change. Given the complexity of each of the subsystems, not to mention the complexity of the interactions, it seems unlikely that any single person can comprehend the whole set of implications that a given change project might precipitate. However, it is not only feasible, but actually highly recommendable, that all of the persons involved in any major change project (mangers, physicians, engineers) have at least a broad systemic understanding of how their decisions might affect other subsystems of the organization.

The current work leads us to make the following recommendations regarding technology-led change:

1. Changes in technology have effects that go beyond the technology arena. A new technology can unbalance other key organizational subsystems. Successfully assimilating a new technology requires that these other organizational subsystems absorb these disruptions and adapt to a new equilibrium. Failing to achieve a new equilibrium will most likely result in a frustrating waste of time and resources. This equilibrium must be viewed along both vertical and horizontal dimensions.

2. Vertical fit refers to the alignment between the new technology, the capabilities of the organization and its strategy. There are no universally good technologies. A technological innovation will add value to the organization if and only if it can contribute to generating the capabilities that are necessary for the organization to achieve its objectives.

3. Horizontal fit refers to the integration between the social and technical subsystems of the organization. For an organization to be able to successfully adopt a new technology, it will have to adapt its structure and its human resource architecture in a way that allows the new technology to be used by the right people in the right way and at the right times.

4. As far as organizational structure, changes in the organization's core technology will often challenge existing procedures and decision making policies, and will force the modification of existing jobs and job assignments.

5. In relation to the people subsystem, we have argued that the concept of culture, understood as the norms, values and basic assumptions shared by the people in the organization, can provide a valuable medium to assess and manage change. There are three main sources of culture at work: national culture, occupational culture and organizational culture.

\section{References}

Argyris, C., \& Schön, D. A. (1978). Organizational learning: A theory of action perspective. Reading, MA: Addison Wesley. 
Cabrera, E. F., \& Bonache, J. (1998). An expert HR system for aligning organizational culture and strategy. Human Resource Planning, 22(1), 5160.

Cooper, R., \& Markus, M. L. (1995). Human reengineering. Sloan Management Review 36(4), 3950.

Hammer, M. (1996). Beyond reengineering. New York: HarperCollins.

Hammer, M., \& Champy, J. (1993). Reengineering the corporation. New York: HarperCollins.

Higgins, J. M. (1996). Innovate or evaporate: Creative techniques for strategists. Long Range Planning, 29(3), 370380.

Hofstede, G. (1980). Culture's consequences. Beverly Hills, CA: Sage.

Hofstede, G. (1991). Cultures and organizations: Software of the mind. Beverly Hills, CA: Sage.

Hofstede, G., Neuijen, B., Ohayv, D. D., \& Sanders, G. (1990). Measuring organizational cultures: A qualitative and quantitative study across twenty cases. Administrative Science Quarterly, 35, 286316.

Miles, R. E., \& Snow, C. C. (1978). Organizational strategy, structure and process. New York: McGraw Hill.

Kirn, S. (1997). Cooperative knowledge processing. In S. Kirn, \& G. O’Hare (Eds.), Cooperative Knowledge Processing. Berlin: Springer.

Miller, D. (1993). The architecture of simplicity. Academy of Management Review, 18, 116138.

Miller, D. (1994). What happens after success: The perils of excellence. Journal of Management Studies, $31(3), 325358$.

Mintzberg, H. (1978). Patterns in strategy formulation. Management Science, 24(9), 934948.

Ouchi, W. G. (1981). Theory Z. Reading, MA: Addison Wesley.

Pasmore, W. A. (1988). Designing effective organizations: The sociotechnical systems perspective. New York: Wiley.

Peters, T. J., \& Waterman, R. H. (1982). In search of excellence: Lessons from America's best run companies. New York: Harper \& Row.

Porter, M. E. (1980). Competitive strategy: Techniques for analyzing industries and competitors. New York: Free Press.

Porter, M. E. (1996). What is strategy? Harvard Business Review, 74(6), 6178.

Reichers, A. E., Wanous, J. P., \& Austin, J. T. (1997). Understanding and managing cynism about organizational change. Academy of Management Executive, 11(1), 4859.

Ruddle, K., \& Feeny, D. (1997). Transforming the organisation: New approaches to management, measurement and leadership. Oxford Executive Research Briefing, Templeton College, Oxford University.

Schein, E. H. (1990). Organizational culture. American Psychologist, 45, 109119.

Schein, E. H. (1996). Three cultures of management: The key to organizational learning. Sloan Management Review, 38(1), 920.

Trice, H. M., \& Beyer, J. M. (1993). The cultures of work organizations. Englewood Cliffs, NJ: Prentice Hall.

Ángel Cabrera is Professor of Organizational Behavior and Human Resource Management and Dean at Instituto de Empresa graduate business school in Madrid, Spain. He holds an engineering degree in Telecommunications Engineering from Universidad Politécnica de Madrid, and an M.S. and Ph.D. in Psychology from the Georgia Institute of Technology, which he attended as a Fulbright Scholar. Before joinging Instituto de Empresa he worked as a consultant and manager at Andersen Consulting (now Accenture). His current research focuses on change and knowledge management.

Elizabeth F. Cabrera is Assistant Professor of Human Resource Management and Organizational Behavior at the Universidad Carlos III in Madrid, Spain. She received an undergraduate degree in Business Administration from Rhodes College and M.S. and Ph.D. degrees in Industrial and Organizational Psychology from the Georgia Institute of Technology. Her research interests include HR architectures, organizational culture, and the evaluation of HR systems and interventions. Her research is partially funded by the Spanish Ministry of Science and Technology research grant SEC2000 0395 and the Comunidad de Madrid research grant 06/0065/2000.

Sebastián Barajas is a Director at Deloitte Consulting. He received his undergraduate business degree from the University of Barcelona and his MBA from ESADE business school, also in Barcelona. He was a founding partner of the consulting firm $\mathrm{CMC}$ and later an Associate Partner with Andersen Consulting (now Accenture). His current interests focus on people centered business transformation. 